\title{
Model to Maximize Self-consumption of Olive Mills Powered by a Mixed System of Renewable Energies
}

\author{
O. Rabaza, J. Contreras-Montes, A. Espín-Estrella, D. Gómez-Lorente \\ Department of Civil Engineering \\ E.T.S.I.C.C.P., University of Granada \\ C/ Severo Ochoa S/N, 18071 Granada (Spain) \\ Phone/Fax number: +34 958249 517, e-mail: ovidio@ugr.es
}

\begin{abstract}
In recent years, due to the growth of petroleum prices and gas emissions, the renewable energies have been recommended like feed sources to different types of facilities, and therefore, since 2010 to 2020 the European Commission has established three key objectives related with climatic change and the energy sustainability like are reduction of the $\mathrm{CO}_{2}$ emissions, increase of the use of the renewable energies and the rise of the energy efficiency. A key sector are the produce installations of olive oil also called "olive mills", where there is a great opportunity to reduce the electrical consumption, increase the additional profits related to reduction of harmful technologies to the environment and reduce the costs in its maintenance. For this reason, this paper investigates and compares the technical and environmental feasibility of olive mills, powered by renewable sources such as; solar energy, wind energy, biomass energy or combination of them in Andalusia (South of Spain), having this region a huge energy dependency, but large amount of "green" resources to be used.
\end{abstract}

The feasibility of these systems will be carried out taking into account the cost, power generation, $\mathrm{CO}_{2}$ equivalent emissions and fraction of renewable energy, assuming that they are gridconnected.

\section{Keywords}

Olive mill, sustainability, wind power, solar energy, biomass.

\section{Introduction}

The current situation of energy in Spain and specifically in Andalusia requires from all sectors to consider present and future strategies about the need to save and optimize energy consumption. Climatic change, Kyoto protocol and the needs of the companies to reduce the energy costs, make it necessary to have knowledge of the energy in key sectors [1], as it is the case of the agro-food sector.

The optimization of the energetic consumption in olive mills is a priority among the concerns of the people in charge of its management. However, there is a common interest related to the hiring of the power supply for such facilities as a result of operating for a period of four or five months (since December to April normally). The facilities and electrical supply contracts have been designed for these peaks of consumption, and therefore the installations are "oversized" the rest of the year, it implying unnecessary costs.

\section{Problem}

Since several years the price of the olive oil has touched ceiling, and it is very important to the profitability of the sector reduce the cost of production of the olive oil, therefore it is necessary to focus the effort in the reduction of the energy consumption, one of the costs more significant in this Agro-Food industry.

Despite the fact that the olive mills are simples facilities that invite to think that there are only few points where we can act, this work will demonstrate that it is possible achieve an optimization of the facility, obtaining similar results in the production with less energy consumption.

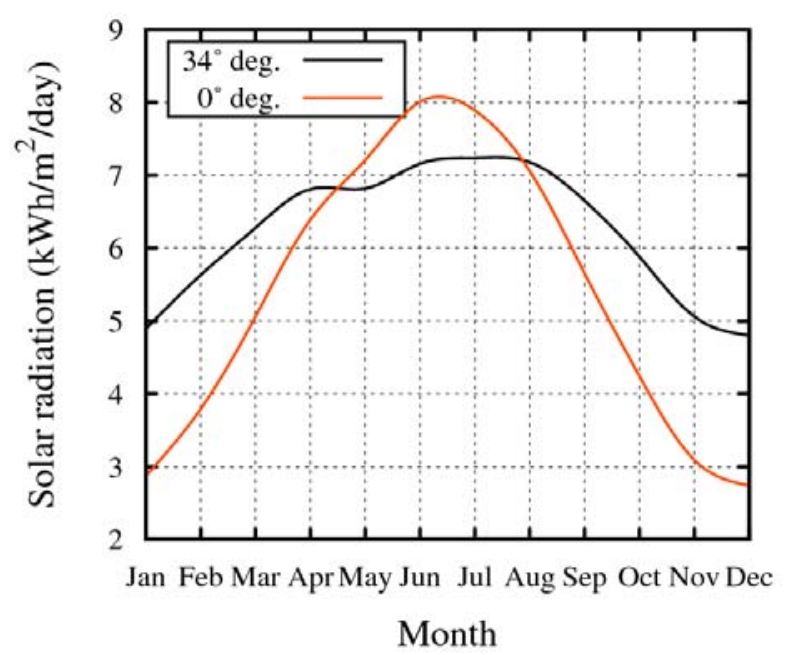

Fig. 1. Monthly solar radiation in the South of Spain using PVGis [2].

Thanks to the reduction of power consumption, the use of renewable energies would be the best solution to reduce the cost in energy and $\mathrm{CO}_{2}$ equivalent emissions to the 
atmosphere, nevertheless not all renewable sources are suitable for this purpose. According to the climatic conditions of Andalusia three types of systems were analyzed; solar energy, wind power and biomass.

Almost the totality of the olive fields and olive mills are located in the south of Spain, whose solar radiation levels is the highest of Europe with an average value each year of $4.93 \mathrm{kWh} / \mathrm{m}^{2} /$ day and about $3.22 \mathrm{kWh} / \mathrm{m}^{2} /$ day during the period that olive mills are working, specifically since November to March (see Fig. 1). These climatic conditions have today allowed the installation of $882 \mathrm{MWp}$ of solar photovoltaic and $1900 \mathrm{MW}$ of solar thermal power in Andalusia.

Regarding to the wind power the characteristics of the wind regimes in Andalusia have allowed the installation of $3400 \mathrm{MW}$, it invites to think about the possibility of the establishment of a wind turbine in the olive mills. In Fig. 2 is shown the average velocity of wind to $40 \mathrm{~m}$ of height.

$(\mathrm{m} / \mathrm{s})$

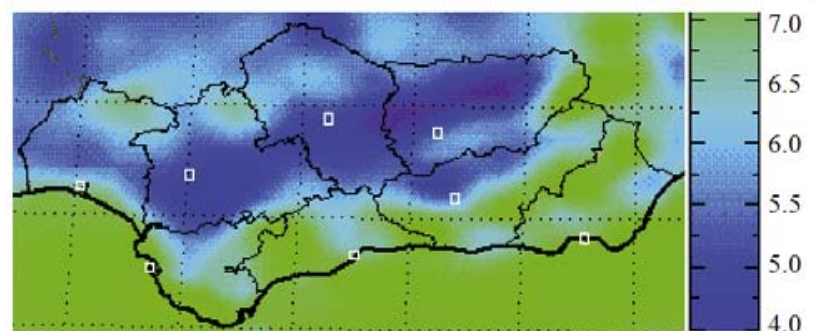

Fig. 2. Wind resource in Andalusia since December to April. Height: 40 m. Source: Andalusia Energy Agency [3].

And finally, the amount of bio-waste from cultivation of the olive grove and oil production (pruning of olive trees and holm oak, olive-pomace oil, olive stones, etc.) are an energy source for the use of bio-fuels in boilers, stoves, ovens, etc. The energy exploitation of biomass allows the sustainable replacement of fossil fuels and it increases selfsufficient. In this case, biomass can be used as energy source for electricity and heating [4].

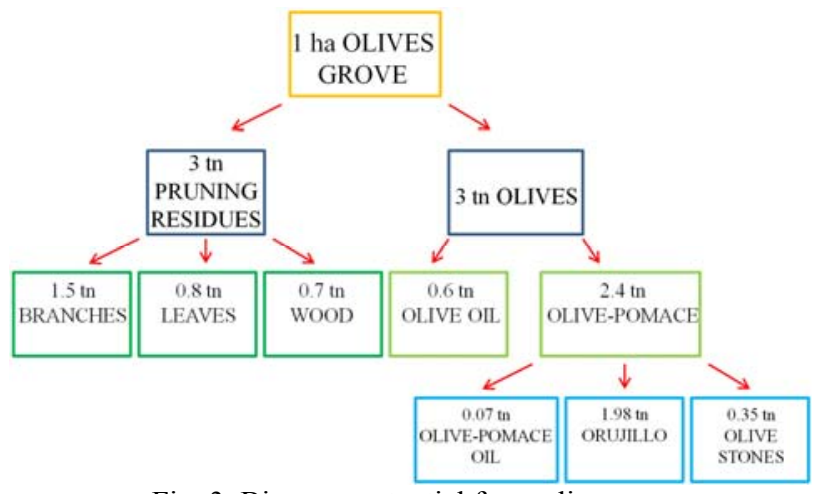

Fig. 3. Biomass potential from olive grove.

Although the resources described above are available in Andalusia, nowadays there is not a study that shows the feasibility in the use of a mixed model (with different types of renewable energies) to minimize energy consumption of the olive mills. Therefore, a model will be shown to optimize the electricity consumption with the aim to maximize the energy saving with the implementation of renewable energies.

\section{Energy Consumption of the Olive Mills}

The energy consumption of olive mills can be divided in electrical and thermal.

The electrical consumption is supplied by the electrical grid and it is located in the stages of cleaning of the fruit (conveyors, bar screens, washing machines, engines, etc.) and grinded (grinders and centrifugal pumps). Thermal consumption corresponds to the needs of hot water to maintain the temperature of the dough mixer around 30 ${ }^{\circ} \mathrm{C}$ and ambient temperature of the cellar between $15{ }^{\circ} \mathrm{C}$ and $20{ }^{\circ} \mathrm{C}$, as well as the hot water of the centrifuges. The water is heated by a boiler that traditionally uses fossil fuels, such as diesel.

In addition to the phases that directly affect the process of the olive oil production, there are other facilities that require electricity for operation such as offices, lighting and air conditioning.

Obviously, the energy consumption will depend of the olive oil production, therefore, in this work the size of the olive mills have been classified according to the following production:

Table I. - Classification of the olive mills according to the final production

\begin{tabular}{|l|c|}
\hline \multicolumn{1}{|c|}{ Classification of mills } & Production of Olive Oil \\
\hline Small & $\leq 1000 \mathrm{tn}$ \\
\hline Medium & ] $1000,5000] \mathrm{tn}$ \\
\hline Large & $>5000 \mathrm{tn}$ \\
\hline
\end{tabular}

The average power consumption of different mills according to their production is shown in Table II:

Table II. - Electrical consumption of the olive mills according to the final production

\begin{tabular}{|l|c|}
\hline \multicolumn{1}{|c|}{ Classification of mills } & Electrical Consumption \\
\hline Small & $92000 \mathrm{kWh}$ \\
\hline Medium & $435000 \mathrm{kWh}$ \\
\hline Large & $922500 \mathrm{kWh}$ \\
\hline
\end{tabular}

And finally, the consumption of thermal energy is shown in Table III:

Table III. - Consumption of thermal energy in olive mills according to the final production

\begin{tabular}{|l|c|}
\hline \multicolumn{1}{|c|}{ Classification of mills } & Electrical Consumption \\
\hline Small & $108000 \mathrm{kWh}$ \\
\hline Medium & $510650 \mathrm{kWh}$ \\
\hline Large & $1082900 \mathrm{kWh}$ \\
\hline
\end{tabular}

With the data shown in the previous tables and the available resources (solar, biomass and wind) we can to develop a model that will allow us to sizing an olive mill with the contribution of renewable energy sources with the objective of maximizing the sustainability of this type of agro-food industry. 


\section{Materials and Methods}

The system was designed by calculating monthly demand of electrical and thermal energy required by an olive mill and the power output of the different combinations of solar PV, biomass and wind turbines. Following points were taken into account in system design:

1) The energy generated as a combination of $P V$, biomass and wind turbine has to be the cheapest and less $\mathrm{CO} 2$ emissions. A biomass boiler provides power to heat the water signposting.

2) Batteries won't be used

3) The AC power from inverter of the system feds to the distribution grid.

4) Maximum power from Renewable systems will be $100 \mathrm{~kW}[5]$.

\section{A. System model}

The proposed system is shown in Fig. 4. The system was designed using HOMER (Hybrid Optimization of Multiple Energy Resources) [6], a micro power optimization model developed and regularly improved by the American National Renewable Energy Laboratory. This application helps to find the best generation system (size and number of components, their costs and environmental impacts). Besides, HOMER is able to evaluate feasibility (economic and technical) of the system.

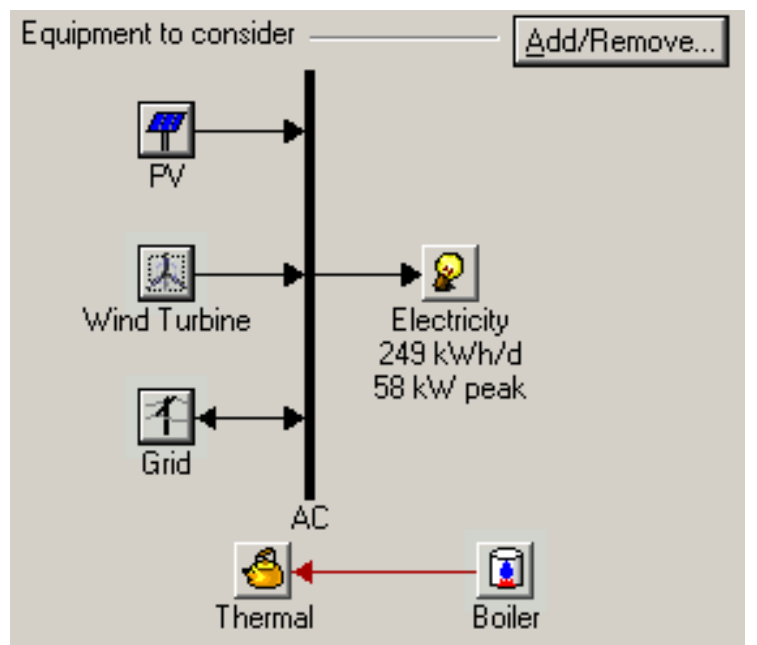

Fig. 4. Basic setting of loads (smaller olive mills) and sources in HOMER.

The used systems that are based on renewable sources which provide power to the processes of the olive mill that consume electricity will be PV modules and wind turbines, always connected to grid (self-consumption). The thermal consumption will be supplied by boilers of biomass.

In this work we will calculate the optimum solution for the three groups of olive mills (smaller, medium and large production) according to the electrical and thermal consumption shown in Tables II and III. In Fig. 5 and 6 is shown the monthly electricity and thermal load profile of a small olive mill. Note that the busiest months range from November to April. In the rest months there is not heat consumption and minimum electrical consumption due to the office facilities (lighting, air-conditioning, etc.).

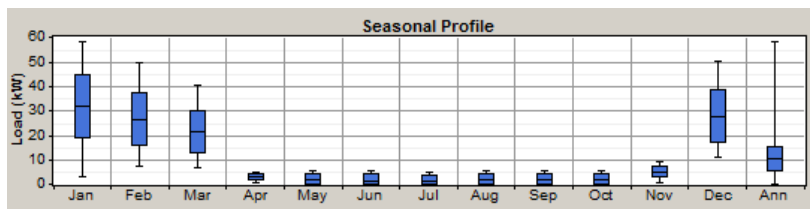

Fig. 5. Monthly electricity load profile of a small olive mill.

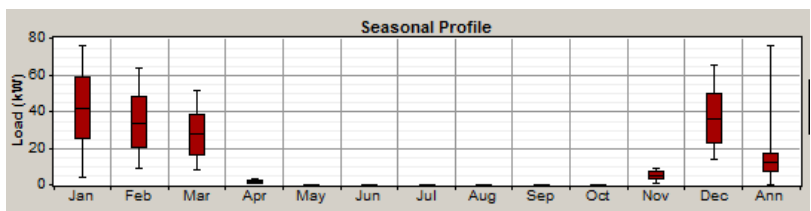

Fig. 6. Monthly thermal load profile of a small olive mill.

\section{B. PV system}

The PV output majorly depends on the available solar radiation. The PV module is designed in this work produces AC. Considered size range from 1 to $100 \mathrm{~kW}$ and the input cost and information is shown Table IV:

Table IV. - PV module cost and characteristics

\begin{tabular}{|l|c|}
\hline Description & Cost/Information \\
\hline Capital cost & $3125 \$ / \mathrm{kW}_{\mathrm{AC}}$ \\
\hline Replacement cost & $2500 \$ / \mathrm{kW} \mathrm{AC}$ \\
\hline Life time & 25 years \\
\hline PV tracking & No tracking \\
\hline De-rating factor & $80 \%$ \\
\hline Slope (degrees) & 37.1667 \\
\hline Ground reflectance & $20 \%$ \\
\hline
\end{tabular}

The average price shown in Table IV refers to PV modules installed.

The main feature of the HOMER software is that it will gives the solar radiation levels once the latitude and longitude coordinates have been specified. The solar radiation is shown in Fig. 7, where the proposed site location is $37^{\circ} 10^{\prime}$, North Latitude and $3^{\circ} 36^{\prime}$ West Longitude. Annually an average of $4.93 \mathrm{kWh} / \mathrm{m}^{2} / \mathrm{d}$ of solar radiation is available.

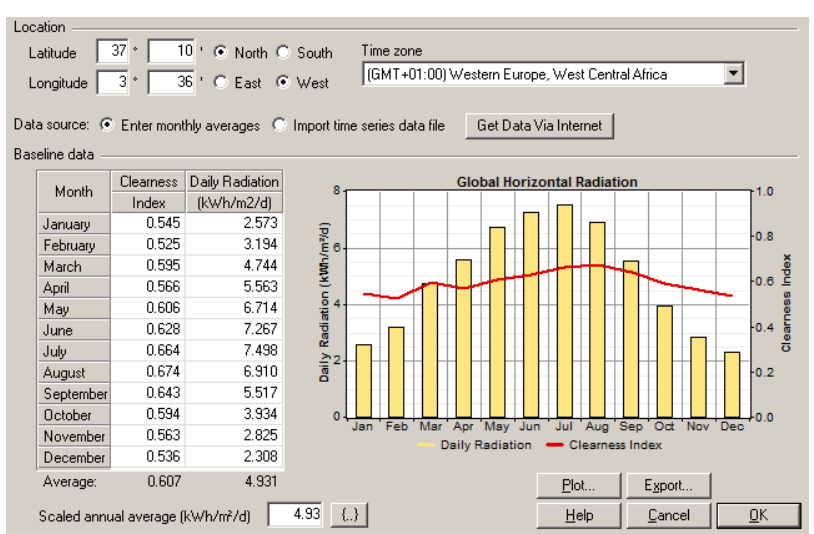

Fig. 7. Calculations of the monthly radiation in the South of Spain using HOMER software. 


\section{Wind turbine}

The Wind turbine output depends on the available average velocity of wind. According to Fig. 2, the average velocity used is $5.5 \mathrm{~m} / \mathrm{s}^{2}$ to $40 \mathrm{~m}$ of height. The Wind turbine designed in this work produces AC. Considered size range from 1 to $100 \mathrm{~kW}$ the cost is shown in Fig. 8.

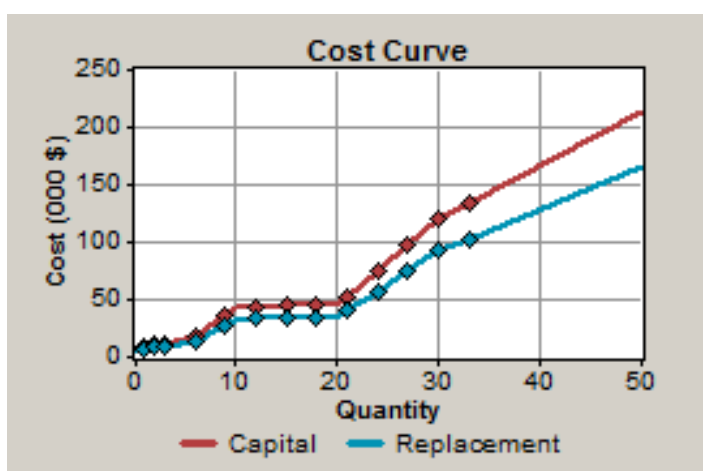

Fig. 8. Cost of Wind turbine as function of power installed and the cost of replacement.

\section{Biomass boiler}

Biomass is provided by the amount of bio-waste of cultivation of grove and olive oil production (pruning of olive trees and Holm oak, olive pomace oil, olive stones, etc.). The elements obtained from cultivation have different properties thermal, of density, etc., therefore in this work we have used an averaged value of every physical feature weighted with the amount of waste in production (see Fig. 3).

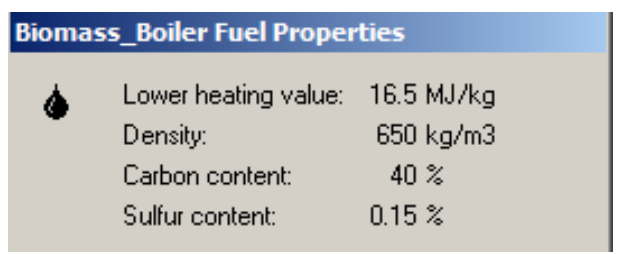

Fig. 9. Biomass properties used to the model in HOMER.

The efficiency of the boiler is $85 \%$.

\section{E. Grid}

The cost of electrical energy is taken to be $0.121 \$ / \mathrm{kWh}$ off-peak rate, $0.195 \$ / \mathrm{kWh}$ shoulder rate and $0.255 \$ / \mathrm{kWh}$ peak rate for purchase and $0.058 \$ / \mathrm{kWh}$ for sale back to the grid. The monthly fee charged only for the use of the electrical infrastructure is $3.1 \$ / \mathrm{kW} /$ month.

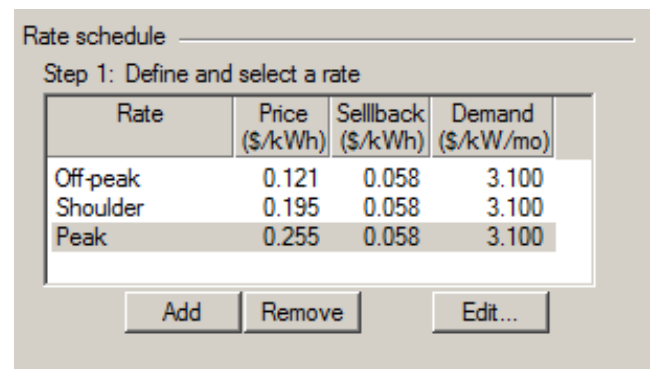

Fig. 10. Cost of current tariff in electrical energy implemented HOMER.
Finally, it is necessary to indicate in that time of the year is applied each of the rates in order to improve the optimization in the contribution of each system, renewable or network connection.

In Fig. 11 is shown the yearly rate schedule implemented in the software.

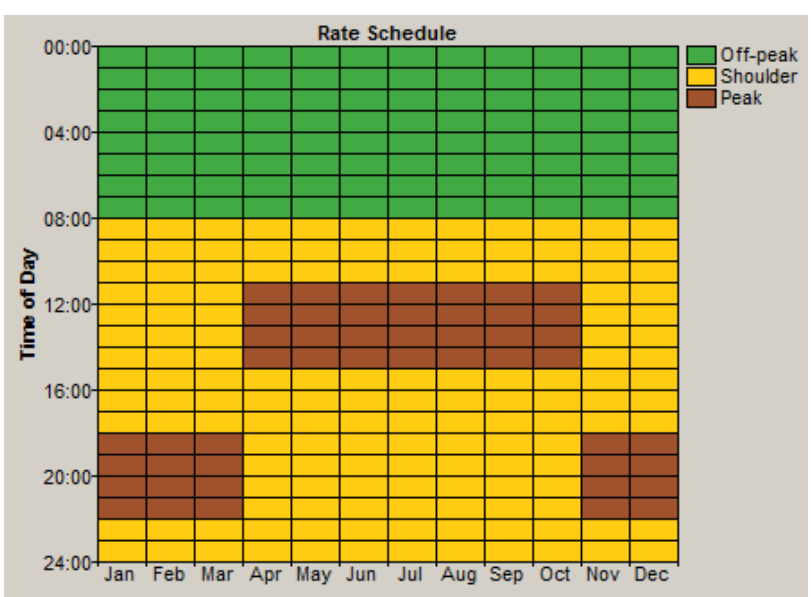

Fig. 11. Rate schedule implemented in HOMER.

\section{Optimization Result and Model}

The optimization result for the small olive mills indicates that the best optimal system is designed only with PV modules connected to grid and biomass with $0.2 \$ / \mathrm{kWh}$ Cost Of Energy (COE), and far away from this optimal solution we find a solution by using a hybrid PV-Wind turbine connected to grid.

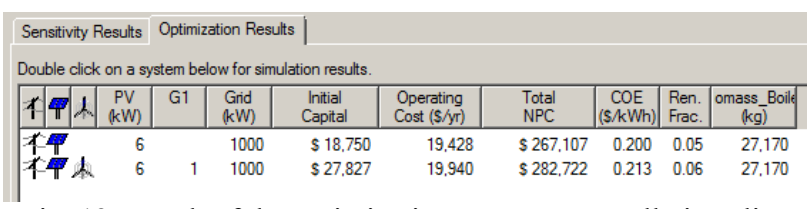

Fig. 12. Result of the optimization process to small-size olive mills.

Following the same procedure with medium and large olive mills, the following results are obtained:

\begin{tabular}{|c|c|c|c|c|c|c|c|c|}
\hline Sensitivity Results & \multicolumn{8}{|c|}{ Optimization Results | } \\
\hline \multicolumn{9}{|c|}{ Double click on a system below for simulation results. } \\
\hline \begin{tabular}{|c|c|c|c|c|c|c|c|} 
\\
$(\mathrm{kW})$
\end{tabular} & G1 & $\begin{array}{l}\text { Gind } \\
(\mathrm{kW})\end{array}$ & $\begin{array}{l}\text { Initial } \\
\text { Capital }\end{array}$ & $\begin{array}{l}\text { Operating } \\
\text { Cost (s/yr) }\end{array}$ & $\begin{array}{l}\text { Total } \\
\text { NPC }\end{array}$ & \begin{tabular}{|c|}
$\left.\begin{array}{c}C O E \\
(S / k W h\end{array}\right)$ \\
\end{tabular} & $\begin{array}{l}\text { Ren. } \\
\text { Frac. }\end{array}$ & \begin{tabular}{|c|} 
omass_Boile \\
$(\mathrm{kg})$
\end{tabular} \\
\hline 14 & & 1000 & $\$ 87,50$ & 91,731 & $\$ 1,260.131$ & 0.200 & 0.05 & 128.730 \\
\hline 28 & 1 & 1000 & $\$ 96,57$ & 92,236 & $\$ 1,275,657$ & 0.203 & 0.05 & 128,730 \\
\hline
\end{tabular}

Fig. 13. Result of the optimization process to medium-size olive mills.

\begin{tabular}{|c|c|c|c|c|c|c|c|c|c|}
\hline \multicolumn{2}{|c|}{ Sensitivity Results } & \multicolumn{8}{|c|}{ Optimization Results } \\
\hline \multicolumn{10}{|c|}{ Double click on a system below for simulation results. } \\
\hline $1 \% 1$ & $\begin{array}{c}\mathrm{PV} \\
(\mathrm{kW})\end{array}$ & G1 & $\begin{array}{l}\text { Gind } \\
(\mathrm{kW})\end{array}$ & $\begin{array}{c}\text { Initial } \\
\text { Capital }\end{array}$ & $\begin{array}{l}\text { Operating } \\
\text { Cost }(\$ / y r)\end{array}$ & $\begin{array}{l}\text { Total } \\
\text { NPC }\end{array}$ & \begin{tabular}{|c|c|}
$\begin{array}{c}C O E \\
(s / k W h)\end{array}$ \\
$(S k$.
\end{tabular} & \begin{tabular}{|l} 
Ren. \\
Frac.
\end{tabular} & $\begin{array}{c}\text { omass_Boile } \\
(\mathrm{kg})\end{array}$ \\
\hline 本 & $\begin{array}{l}40 \\
40\end{array}$ & 1 & $\begin{array}{l}1000 \\
1000\end{array}$ & $\begin{array}{l}\$ 125,000 \\
\$ 134,077\end{array}$ & $\begin{array}{l}200,010 \\
200,492\end{array}$ & $\begin{array}{l}\$ 2,681,796 \\
\$ 2,697,039\end{array}$ & $\begin{array}{l}0.201 \\
0.202\end{array}$ & $\begin{array}{l}0.03 \\
0.03\end{array}$ & $\begin{array}{l}273,012 \\
273,012\end{array}$ \\
\hline
\end{tabular}

Fig. 14. Result of the optimization process to large-size olive mills.

According to the results shown in Fig. 12, 13 and 14 we conclude that the optimum combination is a mixed system with PV system connected to grid (focused to 
electrical consumption) and Biomass boiler (thermal supply). Therefore, the relationships between the olive oil production and the energy support from renewable systems is summarized in the next table:

Table VI. - Relationship between olive oil production and renewable energy support

\begin{tabular}{|l|c|}
\hline \multicolumn{1}{|c|}{ Classification of mills } & PV module $(\mathrm{kW})$ \\
\hline 1000 tn (small-size) & 6 \\
\hline 3000 tn (medium-size) & 28 \\
\hline 5000 tn (large size) & 40 \\
\hline
\end{tabular}

\section{kW PV module - olive oil production}

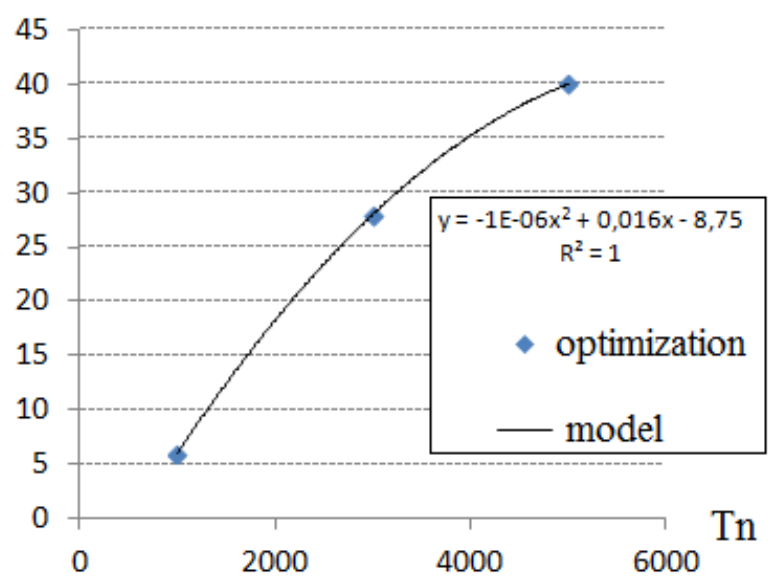

Fig. 15. Polynomial fit of the optimization results.

The model obtained expressed as a polynomial, only it is taking into account, wind velocities of $5.5 \mathrm{~m} / \mathrm{s}$, for this reason a solution with wind turbine is not the cheapest.

Regarding to the biomass, in Fig. 3 we can see that, for each 0.6 tons of olive oil produced, it is obtained almost 3.5 tons waste useful for biomass (pruning, holm oak, olive-pomace oil, olive stones, etc.), therefore, according to the results shown in Fig. 12, 13 and 14, the biomass boiler is covered with the waste obtained to the olive oil production.

Obviously, the olive mills in Andalusia do not have similar conditions of wind velocity; therefore one line of research followed by the authors will be the implementation of a wide range of wind velocities in the model and the implementation of the model in a GIS system [7, 8] where we will cross the data of wind, as well as the olive mills in Andalusia, whose production data are known. As result, each olive mill will have different $a_{j}$ parameters (polynomial coefficients) optimized according with its surrounding.

\section{Conclusions}

The results obtained by using HOMER software allow us to have a realistic and simple model to plan the energy supply (Electrical and Thermal) based on low-carbon technologies for olive mills as function of its production.
Amount of yearly energy production, consumption and finally COE have been obtained at different conditions of production to get the optimum system. The analysis reveals that COE is $0.2 \$ / \mathrm{kWh}$ in case of the grid connected system, lower as compared to grid only system. This is advantageous in context of economy.

The optimized study of a mixed system for olive mill showed that the proposed system by the model can be implemented in a cost effective and environmentally friendly way.

\section{References}

[1] M. Soshinskaya M., W.H.J. Crijns-Graus, J. Van der Meer, J.M. Guerrero. "Application of a microgrid with renewables for a wáter treatment plant". Applied Energy. Vol 134, pp. 20-34, 2014.

[2] The Photovoltaic Geographical Information System (PVGIS). http://re.jrc.ec.europa.eu/pvgis/.

[3] Andalusia Energy Agency. Recurso Eólico de Andalucía, Agencia Andaluza de la Energía, Sevilla (2009), pp. 63-69.

[4] A. García-Maraver, M. Zamorano, A. Ramos-Ridao, L.F. Díaz. "Analysis of olive grove residual biomass potential for electric and thermal energy generation in Andalusia (Spain)". Renewable and Sustainable Energy Reviews. Vol. 16, pp. 745$751,2012$.

[5] Real Decreto 1699/2011. Regulación de conexiones a red de instalaciones de producción de energía eléctrica de pequeña potencia. Ministerio de Industria, Turismo y Comercio de España.2011.

[6] The HOMER Software (HOMER Energy). http://www.homerenergy.com/software.html

[7] J. Arán Carrión, A. Espín Estrella, F. Aznar Dols, M. Zamorano Toro, M. Rodriguez, A. Ramos Ridao. "Environmental decisión-support systems for evaluating the carrying capacity of landa reas: Optimal site selection for gridconnected photovoltaic power plants". Renewable and Sustainable Energy Reviews. Vol. 12, pp. 2358-2380, 2008.

[8] J.A. Carrión, A. Espín Estrella, F. Aznar Dols, A.R. Ridao. "The electricity production capacity of photovoltaic power plants and the selection of solar energy sites in Andalusia (Spain)”. Renewable Energy. Vol. 33, pp. 545-552, 2008. 